\title{
Long term conservative approach in a young male with solitary rectal ulcer syndrome
}

\begin{abstract}
The solitary rectal ulcer syndrome is a rare entity commonly occurring in young patients. A young male presented with symptoms of tenesmus, passage of mucus and blood per rectum. Empirical treatment with anti amoebic therapy was not effective. Endoscopy revealed two ulcers of about $2 \mathrm{~cm}$ diameter located in the anterior rectal wall. The endoscopic appearance was suggestive of solitary rectal ulcer syndrome. The patient was treated with combined sucralfate and prednisolone enema for one week. This was followed with only sucralfate enema for further two weeks. Bulk laxative ispgoal husk was given with fresh yoghurt and biofeedback therapy given continuously to this patient as long term conservative approach. Follow up endoscopy revealed no ulcers after one year. So long term conservative therapy is recommended in all patients with solitary rectal ulcer syndrome.
\end{abstract}

Keywords: SRUS, solitary rectal ulcer, rectal ulcer, suralfate enema
Volume 6 Issue 5 - 2017

\author{
Bhavinder K Arora \\ Professor of Surgery, Pt B D Sharma University of Health \\ Sciences PGIMS, India
}

Correspondence: Bhavinder K Arora, Professor of Surgery, Pt B D Sharma University of Health Sciences PGIMS, India, Tel +91 9466290707,Email drbhavinderarora@gmail.com

Received: April 29, 2017 | Published: May 12, 2017

\section{Abbreviation: SRUS, solitary rectal ulcer syndrome}

\section{Introduction}

Solitary rectal ulcer syndrome is an ulcer commonly in the anterior rectal wall. The ulcer is considered as traumatic lesion due to straining at defecation or digital evacuation of stools. The straining is due constipation or other functional disorders of defecation. SRUS is rare condition presenting with rectal bleeding, mucous and pus. ${ }^{1}$ Although it is a benign condition but difficult to diagnose and treat. Diagnosis can be made by clinical suspicion only. Endoscopic appearance is variable so biopsy should always be taken for confirmation of diagnosis. There may be single ulcer in anterior rectal wall, multiple ulcers or circumferential ulcer in SRUS. Rarely non-ulcerated polypoid lesions and erythematous areas may be seen. ${ }^{2}$ To detect the causative disorder in solitary rectal ulcer syndrome; defecography, transrectal ultrasonography or anorectal manometery are the appropriate investigations. ${ }^{3}$ The clinical presentations of solitary rectal ulcer syndrome may be variable, endoscopic picture may be confusing but histopathologic features are SRUS are characteristic. ${ }^{4}$ Conservative treatment consists of different types of enemas, bulk laxatives and biofeedback. The operative treatment is reserved for patients not responding to conservative treatment. The operative treatment modalities are rectopexy, rectal mucosectomy, segmental colonic resection, local excision and colostomy. ${ }^{5}$ We report one case of SRUS presenting as erythematous area in anterior rectal wall treated with sucralfate and prednisolone enemas.

\section{Case summary}

A 24years male presented with history of passing stool three to four times per day. He felt constipated. He was having a sensation to pass stools many times a day. Every time he went to pass stools he was passing small amount of well formed stools with straining at stools. He was passing small quantity of mucous along with stools. Oral metronidazole $400 \mathrm{mg}$ thrice daily along with syrup lactulose was prescribed for seven days with clinical diagnosis of amoebic proctocolitis. There was no relief in symptoms. After another ten days the patient was passing stools along mucous and blood three to four times per day. The colonoscopy was done in this patient with report as two ulcers on the anterior rectal wall. The ulcers were circular about $2 \mathrm{~cm}$ diameter having greyish white floor with raised margin. There was hyperaemia all around (Figure 1). On endoscopic appearance the diagnosis of solitary rectal ulcer syndrome (SRUS) was suggested. The biopsy from the margin of ulcer revealed chronic inflammatory cells and fibroblast in the lamina propria. The patient was treated by conservative treatment which consisted of bulk laxative.

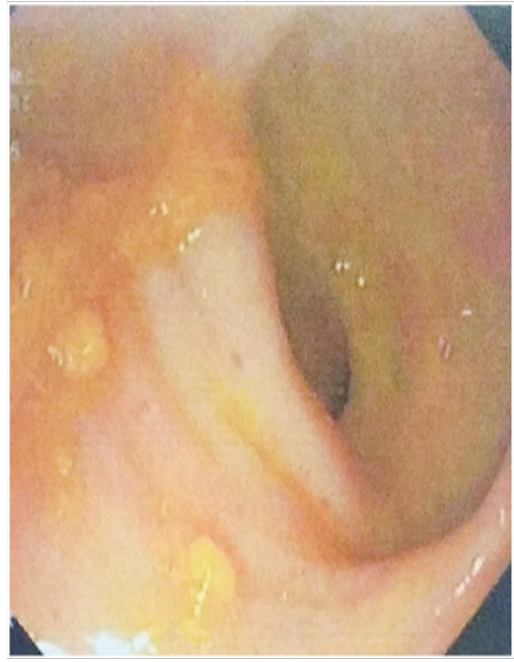

Figure I Endoscopic view of Solitary Rectal Ulcer Syndrome.

The isapgoal husk was given to the patient 2 teaspoonful twice daily in fresh yoghurt. The patient was given clinidium bromide thrice daily for relief of tenesmus. The patient was given sucralfate enema $30 \mathrm{ml}$ dissolved in equal quantity of water was given thrice daily. The prednislone enema was given twice daily alternating with sucralfate enema. These two enemas were given for one week. The sucralfate enema was continued for further two weeks. The biofeedback therapy was advised. The patient improved dramatically with all symptoms disappeared in these three weeks. Long term follow up treatment advised was isapgoal husk 2 teaspoonfuls in fresh yoghurt daily. One 
year follow up this patient has no symptoms and no ulcer in rectum (Figure 2).

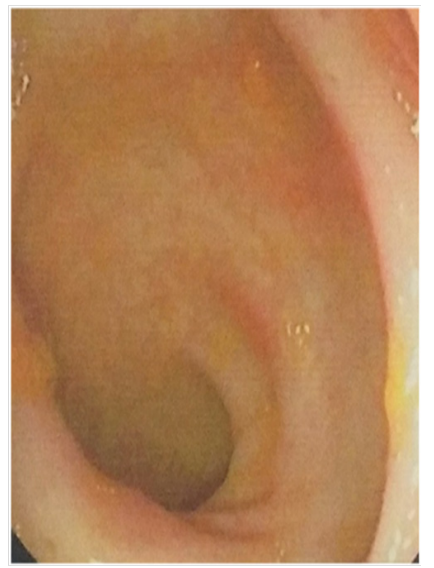

Figure 2 Endoscopic view of healed ulcers.

\section{Discussion}

The clinical entity solitary ulcer of rectum was described by Madigan et al. ${ }^{6}$ The SRUS commonly affects the young patients. The most frequent clinical symptom is bleeding per rectum. Other symptoms are abdominal pain, anorectal pain during defecation, constipation, tenesmus and mucous discharge. These patients have altered bowel habits. There are several etiological factors in formation of SRUS. Constipation with chronic straining at defecation causing ulceration is the most acceptable etiological factor. High anal pressure causing incomplete evacuation in obstructed defecation, internal anorectal intussusceptions and descending perineal syndrome, is another aetiological factor. Mechanical trauma due to digital self evacuation is another attribute. ${ }^{7}$ Massive rectal bleeding is a rare presentation of circumferential SRUS. ${ }^{8}$ Solitary rectal ulcer syndrome (SRUS) is a rare disorder of rectum. The endoscopic picture of a bleeding SRUS is difficult to differentiate from other causes of rectal bleeding. The ulcer was treated by endoscopic haemostasis using argon plasma coagulation. ${ }^{9}$ Although SRUS denominates a single ulcerative lesion in rectum but the multiple, polypoidal or circumferential lesions do occur. The anterior wall is a common site of ulceration in SRUS because anterior rectal mucosa is more mobile and forms lead part of the anorectal intussusceptions. The size of rectal ulcer in various studies varies from 0.5 to $5 \mathrm{~cm}$. The relationship of size of rectal ulcer in SRUS with symptoms is yet to be established. The distance of rectal ulcer from anal verge varies from 4 to $20 \mathrm{~cm}$. The SRUS consists is a shallow, well demarcated ulcer varying in size and number of ulcers. The base of ulcer is covered with greyish white slough. The ulcer is irregular in shape with raised or polypoid edge..$^{10}$ The histopathology shows chronic inflammatory cells and fibroblasts in the lamina propria often associated with smooth muscle hypertrophy. Chiang et al studied the endoscopic pictures and clinicopathological features of solitary rectal ulcer syndrome. The study of varied macroscopic presentations of SRUS leads to correct diagnosis and appropriate treatment. The rare incidence of SRUS makes clinical diagnosis difficult. Al-Brahim et al., ${ }^{11}$ studied a series of 13 cases of SRUS with variable clinical presentation. The endoscopic findings can be multiple ulcerations and polyps. The histopathological findings are also variable like surface ulcers, fibromuscular obliteration and crypts distorsion with diamond crypts in a few cases only. ${ }^{12}$

There are many conservative treatment options. The various treatment modalities for treatment of SRUS are bulk formers, laxatives, sucralfate enema, biofeedback and surgery in some cases. Both conservative and operative management have limitations. All the patients should be subjected to conservative treatment except with internal intussusception and prolapse in which surgery may be required. ${ }^{13}$ In conservative treatment mesalamine is the commonly used drug, bulk laxatives are also used. Patient's response to conservative treatment may vary from complete remission to no response. A study stated that topical mesalamine and steroid are not effective. ${ }^{14}$ Bio feedback therapy or behavioural modification includes bowel habit training, avoid excessive straining on defecation and normalization of pelvic floor coordination can improve symptoms and healing SRUS. Dyssynergic pelvic floor descent and defecation can be treated by bio feedback therapy. Long term remission of SRUS is possible using by continuous bio feedback therapy ${ }^{15}$ Botulinum injection into the external anal sphincter is effective in constipation associated with dyssynergia of defecation thereby in treatment of SRUS. In a study by Keshtgar et al., ${ }^{16}$ conservative measures provide symptom free period in $66.6 \%$ of patients at least for 6 months but recurrence is common. ${ }^{16}$ Patient having increased resting sphincter tone along with evacuation disorder should be subjected to botulinum toxin injection into the sphincter. This results in normal resting sphincter pressure and healing of SRUS.

Zargar et al., ${ }^{17}$ treated solitary rectal ulcer syndrome with suralfate retention enemas with good results. ${ }^{17}$ The treatment of SRUS remains unclear and varies from conservative management to operative treatment. Bishop et al recommended a conservative stepwise individualized approach for treatment of SRUS. Conservative treatment includes patients should be reassured about benign nature of this disease. The aim of treatment is to cure the symptoms and achieve complete healing of ulcer. They recommended conservative treatment with dietary fibre, bowel retraining and bulk laxatives. If symptoms persist the next step is sucralfate enema for 6 weeks. This conservative treatment is continued. Bio feedback therapy is added as next step. Only a few patients with occult rectal mucosa will require surgery as next step. However success of surgical procedure should be discussed with patient and choice of surgical procedure should be according to experience of surgeon. ${ }^{18}$ Sucralfate retention enema given twice daily $2 \mathrm{gm}$ of sucralfate suspended in $30 \mathrm{ml}$ of tap water for 6-8weeks may result in healing of ulcer. This treatment reduced frequency of stools and tenesmus. Bleeding also stopped in these patients. Reduction in size of ulcer to the extent of $50 \%$ occurred in these patients. Two out of eight patients had total improvement. The remaining six patients were treated by surgical treatment. ${ }^{19}$ Dehghani et al. ${ }^{20}$ stated that that a high index of suspicion is required to make the clinical and histopathological diagnosis. The squatting position for defecation used traditionally contributes to the formation of SRUS. They concluded that sucralfate enema is a suitable medical treatment for children with SRUS. ${ }^{20}$

Surgery is required in patients who do not respond to conservative treatment with full thickness rectal prolapsed. Stapled transanal rectal resection (STARR), Delrome's procedure or rectopexy are considered best surgical procedures. Laparoscopic ventral mesh rectopexy (LMVR) for internal and external prolapsed causing SRUS also heals the ulcer and improves quality of life.

\section{Conclusion}

The solitary rectal ulcer syndrome presents commonly with 
bleeding per rectum in young patients. For solitary rectal ulcer is the commonest location is anterior rectal wall about 4 to $6 \mathrm{~cm}$ above the anal verge. It may be associated with internal intussusceptions and defecation disorders. Careful selection of patient is required for conservative management. Bulk laxative, sucralfate enema and biofeedback therapy are effective in all sets of patients. It results in stoppage of bleeding per rectum and healing of rectal ulcer. The surgery is reserved for failure of conservative treatment. The bulk laxatives with fresh yoghurt containing lactobacillus and biofeedback therapy can be used as long term maintenance therapy in preventing recurrence of the solitary rectal ulcer syndrome.

\section{Acknowledgements}

None.

\section{Conflict of interest}

The author declares no conflict of interest

\section{References}

1. Gopal DV, Young C, Katon RM. Solitary rectal ulcer syndrome presenting with rectal prolapse, severe mucorrhea and eroded polypoid hyperplasia:case report and review of literature. Can J Gastroenterol. 2001;15(7):479-483.

2. Crespo Perez L, Moreira Vicente V, Redondo Verge C, et al. "The three-lies disease": solitary rectal ulcer syndrome. Rev Esp Enferm Dig. 2007;99(11):663-666.

3. Tandon RK, Atamkuri SP, Mehra NK, et al. Is solitary ulcer a manifestation of a systemic disease? J Clin Gastroenterol. 1990;12(3):286-290.

4. Sharara AI, Azar C, Amr SS, et al. Solitary rectal ulcer syndrome: endoscopic spectrum and review of literature. Gastrointest Endosc. $2005 ; 62: 755-762$.

5. Choi HJ, Shin EJ, Hwang YH, et al. Clinical presentation and surgical outcome in patients with solitary rectal ulcer syndrome. Surg Innov. 2005;12(4):307-313.

6. Madigan MR, Morson BC. Solitary ulcer of the rectum. GUT 1969;10:871-881.

7. Kannappan O, Mathew S, Naalla R. Solitary rectal ulcer syndrome - the masquerader. International Journal of Scientific and Research Publications. 2015;5(5):1-5.
8. Yagnik VD. Massive rectal bleeding: rare presentation of circumferential solitary rectal ulcer syndrome. Saudi J Gastroenterol. 2011;17(4):298.

9. Yazdarpanah K, Shavakhi A, Sanei MH, et al. An unusal endoscopic presentation of solitary rectal ulcer syndrome. Ind J Gastroenterol. 2013;32(1):58-59.

10. Chong VH, Jalihal A. Solitary rectal ulcer syndrome: characteristics, outcomes and predictive profiles for persistent bleeding per rectum. Singapore Med J. 2006;47(12):1063-1068.

11. Chiang JM, Changchien CR, Chen JR. Solitary rectal ulcer syndrome: an endoscopic and histological presentation and literature review. Int $J$ Colorectal Dis. 2006;21(4):348-356.

12. Al-Brahim N, Al-Awadhi N, Al-Enezi S, et al. Solitary rectal ulcer syndrome:a clinicopathological study of 13 cases. Saudi J Gastroenterol. 2009;15(3):188-192.

13. Zhu QC, Shen RR, Qin HL, et al. Solitary rectal ulcer syndrome: Clinical features, pathophysiology, diagnosis and treatment strategies. World J Gastroenterol. 2014;20(3):738-744.

14. Dehghani SM, Malekpour A, Haghighat. Solitary rectal ulcer syndrome in children: A literature review. World J Gastroenterol. 2012;18(45):65416545 .

15. Jarrett ME, Emmanuel AV, Vaizey CJ, et al. Behavioural therapy (biofeedback) for solitary rectal ulcer syndrome improves symptoms and mucosal blood flow. Gut. 2004;53(3):368-370.

16. Keshtgar AS, Ward HC, Sanei A, et al. Botulinum toxin, a new treatmen modality for chronic idiopathic constipation in children:long term follow up of a double blind randomized trial. J Pediatr Surg. 2007;42:672-680.

17. Zargar SA, Khuroo MS, Mahajan R. Sucralfate retention enemas in solitary rectal ulcer. Dis Colon Rectum. 1991;34(6):455-457.

18. Bishop PR, Nowicki MJ. Nonsurgical therapy for solitary rectal ulcer syndrome. Curr Treat Options Gastroenterol. 2002;5(3):215-223.

19. Simsek A, Yagci G, Gorgulu S, et al. Diagnostic features and treatment modalities in solitary rectal ulcer syndrome. Acta Chir Belg. 2004;104(1):92-96.

20. Dehghani SM, Haghighat M, Imanieh MH, et al. Solitary rectal ulcer syndrome in children: a prospective study of cases from southern Iran. Eur J Gastroenterol Hepatol. 2008;20(2):93-95. 